\title{
Effects of bee venom against Propionibacterium acnes-induced inflammation in human keratinocytes and monocytes
}

\author{
JUNG-YEON KIM $^{1 *}$, WOO-RAM LEE ${ }^{1 *}$, KYUNG-HYUN KIM ${ }^{1}$, HYUN-JIN AN ${ }^{1}$, YOUNG-CHAE CHANG ${ }^{1}$, \\ SANG-MI HAN ${ }^{3}$, YOON-YUB PARK ${ }^{2}$, SOK CHEON PAK ${ }^{4}$ and KWAN-KYU PARK ${ }^{1}$ \\ Departments of ${ }^{1}$ Pathology and ${ }^{2}$ Physiology, School of Medicine, Catholic University of Daegu, Daegu 705-178; \\ ${ }^{3}$ Department of Agricultural Biology, National Institute of Agricultural Science and Technology, Wanju 565-851, \\ Republic of Korea; ${ }^{4}$ School of Biomedical Sciences, Charles Sturt University, Bathurst NSW 2795, Australia
}

Received August 27, 2014; Accepted March 30, 2015

DOI: $10.3892 /$ ijmm.2015.2180

\begin{abstract}
Propionibacterium acnes (P. acnes) cause inflammatory acne and play an important role in the pathogenesis of acne by inducing inflammatory mediators. P. acnes contributes to the inflammatory responses of acne by activating inflammatory cells, keratinocytes and sebocytes to secrete pro-inflammatory cytokines such as tumor necrosis factor- $\alpha$ (TNF- $\alpha$ ), interleukin (IL)- $1 \beta$ and IL-8. Bee venom has traditionally been used in the treatment of certain immune-related diseases. However, there has not yet been a robust trial to prove the therapeutic effect of bee venom in skin inflammation. The aim of the present study was to investigate anti-inflammatory properties of bee venom in skin inflammation induced by $P$. acnes using keratinocytes (HaCaT) and monocytes (THP-1). P. acnes is known to stimulate the production of pro-inflammatory cytokines such as IL-1, IL-8, IL-12 and TNF- $\alpha$. In the present study, the production of interferon- $\gamma$ (IFN- $\gamma$ ), IL-1 $\beta$, IL- 8 and TNF- $\alpha$ was increased by $P$. acnes treatment in HaCaT and THP-1 cells. By contrast, bee venom effectively inhibited the secretion of IFN- $\gamma$, IL- $1 \beta$, IL- 8 and TNF- $\alpha$. Furthermore, $P$. acnes treatment activated the expression of IL-8 and toll-like receptor 2 (TLR2) in HaCaT cells. However, bee venom inhibited the expression of IL-8 and TLR2 in heat-killed $P$. acnes. Based on these results, it is concluded that bee venom has an effective anti-inflammatory activity against $P$. acnes in HaCaT and THP-1 cells. Therefore, we suggest that bee venom is an alternative treatment to antibiotic therapy of acne.
\end{abstract}

Correspondence to: Professor Kwan-Kyu Park, Department of Pathology, School of Medicine, Catholic University of Daegu, 3056-6 Daemyung-4-Dong, Daegu 705-718, Republic of Korea E-mail: kkpark@cu.ac.kr

*Contributed equally

Key words: bee venom, Propionibacterium acnes, keratinocytes, monocytes, skin inflammation

\section{Introduction}

Acne vulgaris is the most common skin disease of the pilosebaceous follicle that results in non-inflammatory and inflammatory lesions. Acne induces inflammation at the skin surface of the face, neck, chest or back (1). The pathogenic factors of acne include increased sebum production, ductal cornification, bacterial colonization of the pilosebaceous ducts and inflammation (2,3). Propionibacterium acnes (P. acnes) is one of the major factors contributing to the inflammatory reaction in acne vulgaris (4). A P. acnes challenge occurs and a cascade of inflammatory events then ensues. P.acnes contributes to the inflammatory responses of acne by activating inflammatory cells, keratinocytes and sebocytes to secrete pro-inflammatory cytokines such as interleukin (IL)- $1 \beta$, IL-8 and tumor necrosis factor (TNF)- $\alpha$ (5). Keratinocytes are the first line of defense in the skin immune system and, in conjunction with sebocytes, produce a variety of cytokines and chemokines (6). Monocytes also activate $P$. acnes in an inflammatory nature of acne to secrete pro-inflammatory cytokines such as IL-1 $\beta$, IL- 8 and TNF- $\alpha$ (7). These cytokines, including IL-1 $\beta$, IL- 8 and TNF- $\alpha$, are produced by human keratinocytes and monocytes, and activate neutrophils and macrophages $(6,7)$. In particular, IL-8 is a member of the CXC chemokine family involved in recruitment of leukocytes to the site of inflammation (8).

Various therapeutic agents involving antibiotics for acne have been used to inhibit inflammation or kill bacteria (9). However, antibiotics may lead to the emergence of resistant pathogens and side effects $(10,11)$. Therefore, new therapeutic agents have been developed for acne with a higher therapeutic activity, but fewer side effects $(12,13)$.

Bee venom is composed of several active peptides, including melittin, apamin, adolapin, mast cell-degranulating peptide and enzymes $(14,15)$. Bee venom has been used in the treatment of inflammatory diseases such as rheumatoid arthritis, back pain and skin diseases (16-18). The anticancer properties of bee venom have also been shown in lung cancer cells, breast cancer cells, hepatocellular carcinoma cells and prostate cancer cells (19-21). Previous studies identified that bee venom induced IL- $1 \beta$ and IL-18 release via the activation of cytosolic DNA receptor in cultured keratinocytes (22). 
However, there has not yet been a robust trial to prove a therapeutic effect of bee venom in skin inflammation. In the present study, the anti-inflammatory properties of bee venom were investigated in skin inflammation stimulated by heat-killed $P$. acnes using human keratinocyte and monocyte cell lines.

\section{Materials and methods}

Bee venom collection. The colonies of natural honeybees (Apis mellifera L.) used in the present study were maintained at the National Academy of Agricultural Science (Suwon, Korea). Bee venom was the collecting device (Chung Jin Biotech Co., Ansan, Korea) used in a sterile manner under strict laboratory conditions. In brief, the bee venom collector was placed on the hive, and the bees were administered enough electric shocks to cause them to sting a glass plate from which dried bee venom was later removed by scraping. The collected venom was purified by the methods of Han et al (23). Purified bee venom was stored in a refrigerator for later use. Bee venom used in the experiment was confirmed with size exclusion gel chromatography (AKTA Explorer; GE Healthcare, Pittsburgh, PA, USA) by dissolving in $0.02 \mathrm{M}$ phosphate buffer with $0.25 \mathrm{M} \mathrm{NaCl}$ adjusted to $\mathrm{pH} 7.2$ using a Superdex peptide colum (Amersham Biosciences, GE Healthcare).

Preparation of bacteria. P. acnes (ATCC 6919) was obtained from the Korean Culture Center of Microorganisms (Seoul, Korea) and cultured on Reinforced Clostridium Medium (BD Diagnostics, Sparks Glencoe, MD, USA) at $37^{\circ} \mathrm{C}$ under anaerobic conditions until it reached $\mathrm{OD}_{600}=1.0$ (stationary phase). The cells were harvested by centrifugation at $5,000 \mathrm{x} \mathrm{g}$ for $15 \mathrm{~min}$ at $4^{\circ} \mathrm{C}$. The bacterial pellet was washed three times in $100 \mathrm{ml}$ of phosphate-buffered saline (PBS; pH 7.4) and finally suspended in $10 \mathrm{ml}$ of PBS. The P. acnes suspension was incubated at $80^{\circ} \mathrm{C}$ for $30 \mathrm{~min}$ for the heat-killing reaction. The heat-killed P. acnes suspension was stored at $4^{\circ} \mathrm{C}$ until use.

Cell culture. HaCaT and THP-1 cells were maintained in Dulbecco's modified Eagle's medium (DMEM) and RPMI-1640 medium, respectively, supplemented with $10 \%$ fetal bovine serum and 100 units penicillin-streptomycin antibiotics (Gibco, Gaithersburg, MD, USA). Cells were cultured at $37^{\circ} \mathrm{C}$ in a humidified incubator under $5 \% \mathrm{CO}_{2}$ atmosphere.

HaCaT $\left(5 \times 10^{5}\right.$ cells $\left./ \mathrm{ml}\right)$ and THP-1 $\left(1 \times 10^{6}\right.$ cells $\left./ \mathrm{ml}\right)$ cells were seeded in complete medium for $24 \mathrm{~h}$. The cells were changed to fresh serum-free medium containing the indicated concentration of bee venom (1, 10 and $100 \mathrm{ng} / \mathrm{ml}$; Sigma, St. Louis, MO, USA). After $30 \mathrm{~min}$, the cells were treated with heat-killed P. acnes (1.0x $10^{7}$ colony-forming units $\left./ \mathrm{ml}\right)$ for $8 \mathrm{~h}$.

Cell viability assay. To determine the effects of bee venom on cell viability, the 3-(4,5-dimethylthiazol-2-yl)-2,5-diphenyltetrazolium bromide (MTT) and Cell Counting kit-8 (CCK-8; Dojindo Laboratories, Kumamoto, Japan) assays were performed on the HaCaT and THP-1 cells. HaCaT cells $\left(5.0 \times 10^{4}\right.$ cells/well) were seeded in a 96-well plate and allowed to attach for $24 \mathrm{~h}$. Cells were treated with serum-free media containing bee venom $(1$, 10 and $100 \mathrm{ng} / \mathrm{ml}$ ) for 8, 12 and $24 \mathrm{~h}$. Cells were washed with PBS. MTT was added to each well to a final concentration of
$0.5 \mathrm{mg} / \mathrm{ml}$ followed by incubation for $4 \mathrm{~h}$ at $37^{\circ} \mathrm{C}$ in a humidified incubator containing $5 \% \mathrm{CO}_{2}$. Finally, MTT containing medium was removed by aspiration and $100 \mu \mathrm{l}$ of dimethyl sulfoxide was added to each well. The absorbance value was measured at $540 \mathrm{~nm}$ using a microplate reader (BMG Labtech, Ortenberg, Germany). THP-1 cells $\left(1.0 \times 10^{4}\right.$ cells/well) were seeded in a 96-well plate and incubated with different concentrations of bee venom for 8, 12 and $24 \mathrm{~h}$. After experimental treatment, $10 \mu \mathrm{l}$ of WST-8 solution [2-(2-methoxy-4-nitrophenyl)-3-(4-nitrophenyl )-5-(2,4-disulfophenyl)-2H-tetrazolium, monosodium salt] was added to each well. Plates were incubated for $4 \mathrm{~h}$ at $37^{\circ} \mathrm{C}$. The absorbance value was measured at $450 \mathrm{~nm}$ using a microplate reader (BMG Labtech).

Enzyme-linked immunosorbent assay (ELISA). The concentrations of IFN- $\gamma$, IL- $1 \beta$ and TNF- $\alpha$ in the supernatant of cultured cells were measured using a commercially available ELISA kit (R\&D Systems, Minneapolis, MN, USA), according to the manufacturer's instructions. Reading of the absorbance at $450 \mathrm{~nm}$ was performed by an ELISA reader (BMG Labtech).

Western blot analysis. Cells were lysed in a lysis buffer [50 mmol/1 Tris ( $\mathrm{pH} \mathrm{8.0),} 150 \mathrm{mmol} / 1 \mathrm{NaCl}, 5 \mathrm{mmol} / 1$ EDTA, $0.5 \% \mathrm{NP}-40,100 \mathrm{mmol} / 1$ phenylmethylsulfonyl fluoride, $1 \mathrm{~mol} / \mathrm{l}$ dithiothreitol, $10 \mathrm{mg} / \mathrm{ml}$ leupeptin and aprotinin]. After incubation for $30 \mathrm{~min}$ on ice, total extract was centrifuged at $8,000 \times \mathrm{g}$ for $15 \mathrm{~min}$ at $4^{\circ} \mathrm{C}$ and the supernatant was used as total protein extract. Protein samples were separated on $8-12 \%$ SDS-polyacrylamide gels and transferred to polyvinylidene fluoride membrane (Millipore, Billerica, MA, USA) using standard SDS-PAGE gel electrophoresis procedure. Membranes were incubated with primary antibodies for $4 \mathrm{~h}$ and horseradish peroxidase (HRP)-conjugated secondary antibodies (sc-2004 and sc-2005) were used for detection. Signals were detected using an enhanced chemiluminescence detection system (Amersham Biosciences Corp., Piscataway, NJ, USA) and film. Primary antibodies used in the present study were anti-TNF- $\alpha$ (ab1793; Abcam, Cambridge, MA, USA), anti-IL-1 $\beta$ (sc-7884), anti-TLR2 (sc-10739) and anti-GAPDH (sc-32233; Santa Cruz Biotechnology, Inc., Dallas, TX, USA). Signal intensity was quantified by an image analyzer (LAS-3000; Fuji, Tokyo, Japan).

Immunofluorescence staining. Visual identification expression of IL-8 through TLR2 was achieved by Hoechst 33342 staining of cells. For Hoechst evaluation, heat-killed P. acnes-treated $\mathrm{HaCaT}$ cells were fixed using $4 \%$ paraformaldehyde for $5 \mathrm{~min}$, followed by $2 \mu \mathrm{g} / \mathrm{ml}$ Hoechst staining at $37^{\circ} \mathrm{C}$ for $30 \mathrm{~min}$. Antibodies used in the experiments were IL-8, TLR2 (Santa Cruz Biotechnology, Inc.), and anti-goat- and anti-rabbit-biotinylated secondary antibodies conjugated with fluorescein isothiocyanate (Invitrogen, Carlsbad, CA, USA) or Texas Red (Invitrogen). Stained nuclei were observed under fluorescence microscopy (Nikon, Tokyo, Japan).

Statistical analysis. The experimental results are expressed as mean \pm standard error. Analysis of variance and paired or unpaired t-tests were performed for statistical analysis as appropriate. $\mathrm{P}<0.05$ was considered to indicate a statistically significant difference. 
A
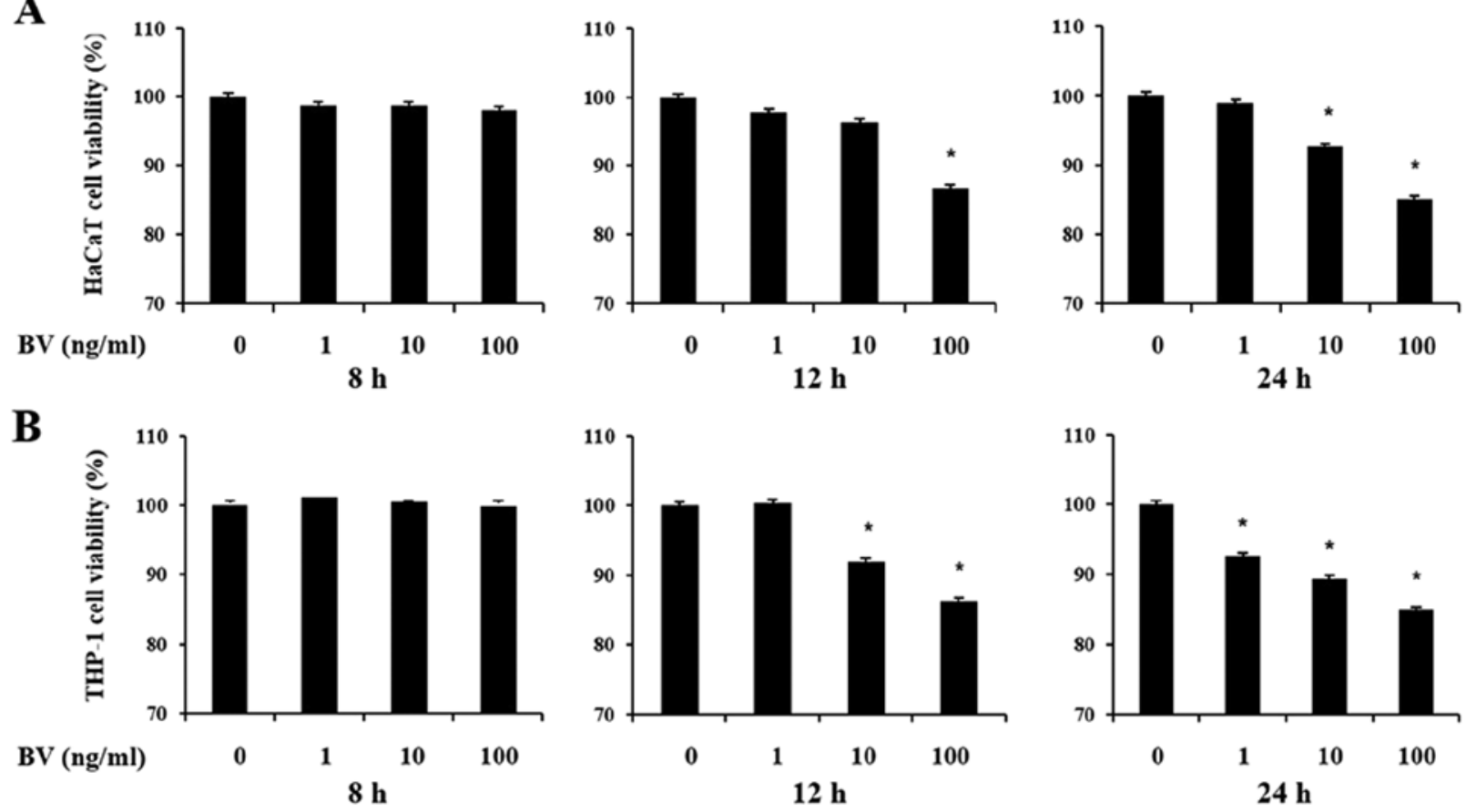

Figure 1. Effects of bee venom (BV) on (A) human keratinocytes (HaCaT) and (B) monocytes (THP-1) cell viability, observed via the MTT and CCK-8 assays, respectively. HaCaT and THP-1 cells were treated with 1,10 and $100 \mathrm{ng} / \mathrm{ml}$ of $\mathrm{BV}$ for 8,12 and $24 \mathrm{~h}$. ${ }^{*} \mathrm{P}<0.05$ vs. untreated cells.
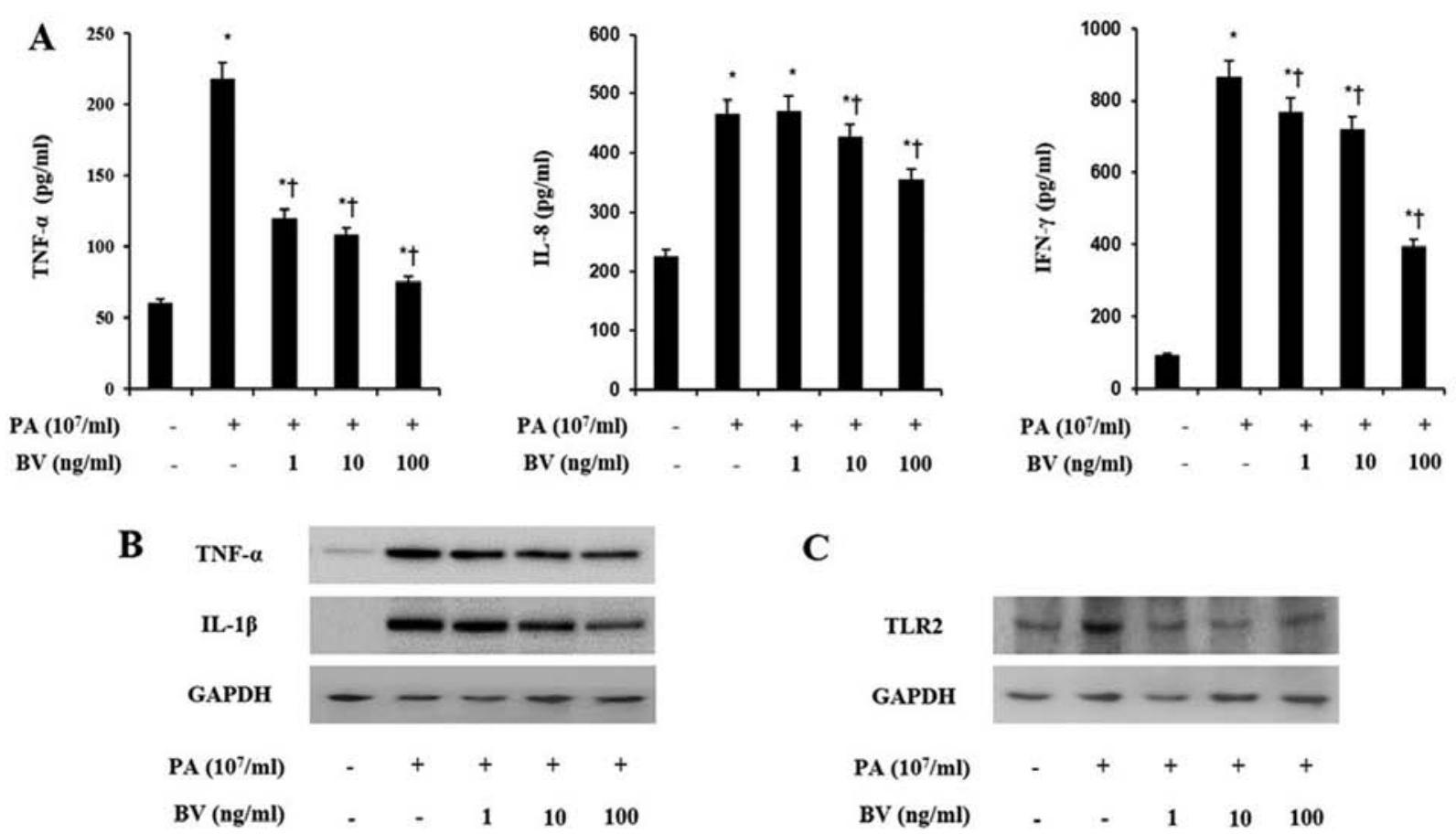

Figure 2. Bee venom (BV) suppresses the pro-inflammatory cytokines, chemokines and toll-like receptor 2 (TLR2) in HaCaT cells. Cells were cultured with bee venom for $8 \mathrm{~h}$ followed by heat-killed P. acnes (PA) treatment. (A) Effects of BV on P. acnes-induced inflammatory cytokines such as tumor necrosis factor- $\alpha$ (TNF- $\alpha$ ), interleukin (IL)-8 and interferon- $\gamma$ (IFN- $\gamma$ ). (B and C) BV inhibited the expression of TNF- $\alpha$ and IL-1 $\beta$, and regulation of TLR2. GAPDH was used as loading control. ${ }^{*} \mathrm{P}<0.05$ vs. untreated cells. ${ }^{\dagger} \mathrm{P}<0.05$ vs. heat-killed $P$. acnes only treatment.

\section{Results}

Effects of bee venom on cell viability. The cytotoxic effects of bee venom were first assessed on the viability of cultured human keratinocytes and monocytes using the MTT and CCK-8 assays, respectively. HaCaT and THP-1 cells were treated with increasing doses of bee venom for 8,12 and $24 \mathrm{~h}$. Decreases in cell viability following treatment with increasing doses of bee venom for 12 and $24 \mathrm{~h}$ were $10-20 \%$ compared to normal untreated cell lines (Fig. 1). However, cells did not lose viability at $8 \mathrm{~h}$ in the presence of bee venom. As a result, cells were treated with bee venom for $8 \mathrm{~h}$ in subsequent experiments. 

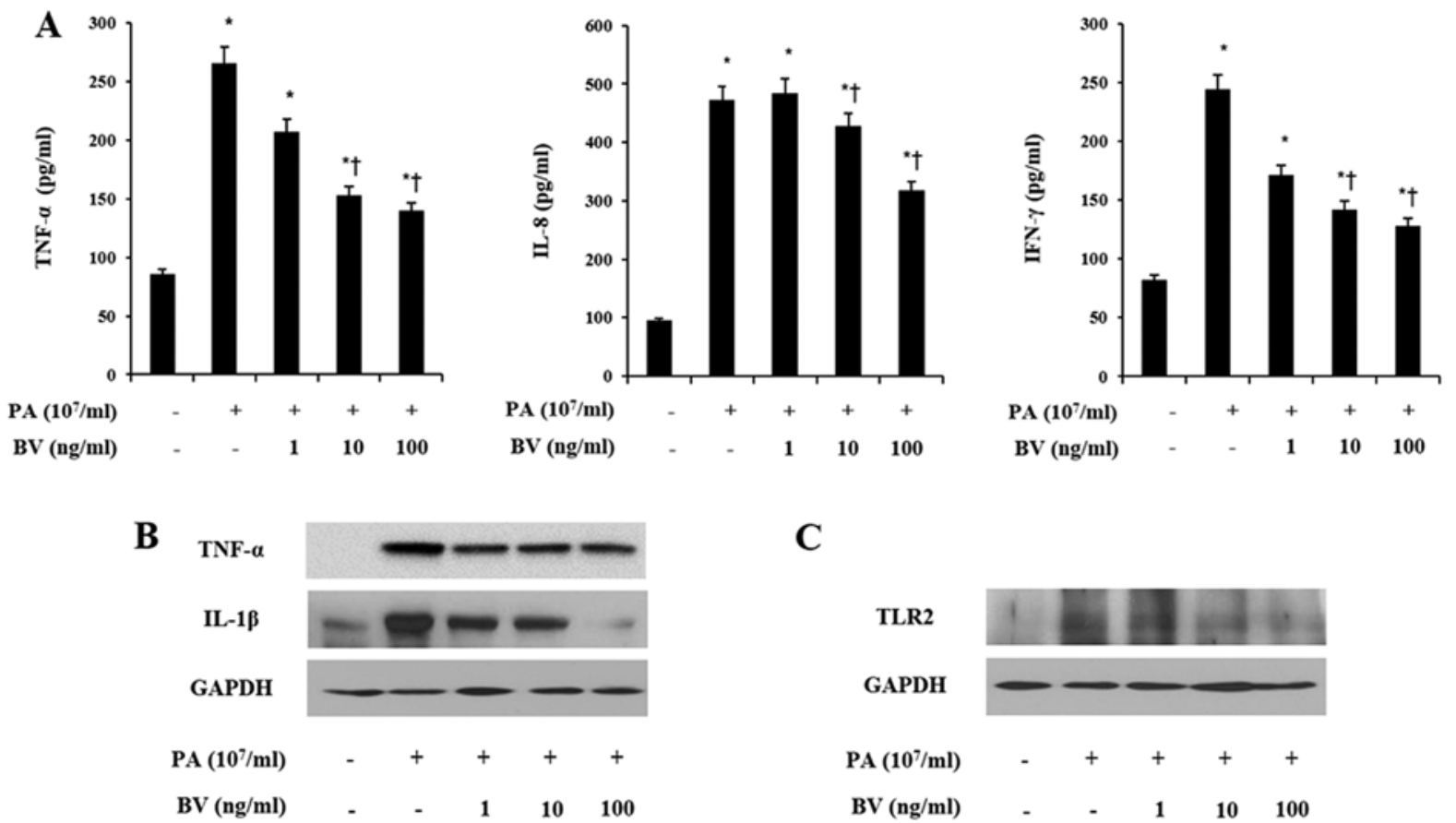

Figure 3. Bee venom (BV) inhibits the pro-inflammatory cytokines, chemokines and toll-like receptor 2 (TLR2) in THP-1 cells. Cells were cultured with $\mathrm{BV}$ for $8 \mathrm{~h}$ followed by heat-killed P. acnes (PA) treatment. (A) Effects of BV on P. acnes-induced inflammatory cytokines such as tumor necrosis factor- $\alpha$ (TNF- $\alpha$ ), interleukin (IL)-8 and interferon- $\gamma$ (IFN- $\gamma$ ). (B and C) BV inhibited the expression of TNF- $\alpha$ and IL-1 $\beta$ and regulation of TLR2. GAPDH was used as loading control. ${ }^{*} \mathrm{P}<0.05$ vs. untreated cells. ${ }^{\top} \mathrm{P}<0.05$ vs. heat-killed $P$. acnes only treatment.
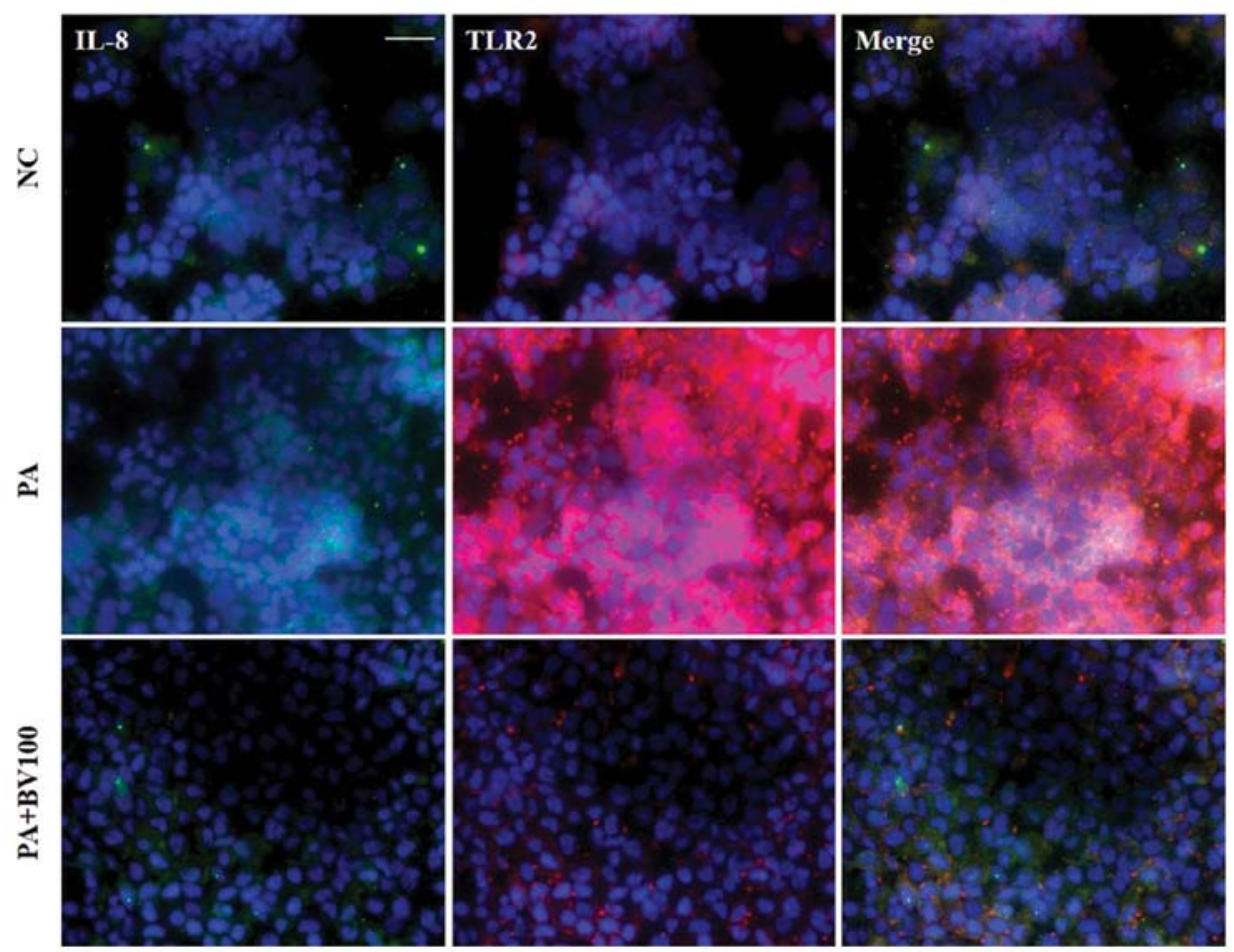

Figure 4. Bee venom (BV) inhibits the expression of interleukin (IL)-8 and toll-like receptor 2 (TLR2) in heat-killed P. acnes-treated HaCaT cells. Immunofluorescence images exhibit that BV treatment decreased expression of IL-8 (fluorescein isothiocyanate, green) and TLR2 (Texas Red) in heat-killed P. acnes-treated HaCaT cells. NC, normal control; PA HaCaT cells treated with heat-killed P. acnes for $8 \mathrm{~h}$; PA+BV100, $100 \mathrm{ng} / \mathrm{ml}$ of $\mathrm{BV}$ was treated for $30 \mathrm{~min}$ followed by co-culture with heat-killed $P$. acnes for $7 \mathrm{~h} 30 \mathrm{~min}$. Magnification, $\mathrm{x} 400$; scale bar, $100 \mu \mathrm{m}$.

Bee venom inhibits the heat-killed P. acnes-induced pro-inflammatory cytokines and chemokine in HaCaT and THP-1 cells. To investigate the anti-inflammatory effects of bee venom in heat-killed $P$. acnes-treated HaCaT and THP-1 cells, ELISA analysis was performed to measure the pro-inflammatory cytokines and chemokines. Cell lines were 
incubated with increasing doses of bee venom for $8 \mathrm{~h}$ and heat-killed $P$. acnes treatment followed. Heat-killed $P$. acnes markedly increased the secretions of TNF- $\alpha$, IL-8 and IFN- $\gamma$ in $\mathrm{HaCaT}$ and THP-1 cells (Figs. 2A and 3A). By contrast, bee venom treatment decreased the secretions of those pro-inflammatory cytokines in HaCaT and THP-1 cells induced with $P$. acnes. These results indicate that heat-killed $P$. acnes effectively induced the secretion of pro-inflammatory cytokines in HaCaT and THP-1 cells. By contrast, bee venom specifically attenuated the secretion of TNF- $\alpha$, IL- 8 and IFN- $\gamma$ in HaCaT and THP-1 cells.

Bee venom suppresses the expression of pro-inflammatory cytokines through TLRs in heat-killed P. acnes-treated HaCaT and THP-1 cells. In order to assess the effects of bee venom on inflammatory changes by $P$. acnes induction, western blot analysis was utilized to analyze the expression of pro-inflammatory cytokines. As shown in Figs. 2B and 3B, heat-killed $P$. acnes strongly increased the expression of TNF- $\alpha$ and IL-1 $\beta$ in HaCaT and THP- 1 cells. By contrast, bee venom significantly suppressed the TNF- $\alpha$ and IL- $1 \beta$ expression in heat-killed $P$. acnes-treated cells. Since the activation of TLRs leads to production of inflammatory cytokines, further western blot analysis was performed on HaCaT and THP-1 cells.

As observed in Figs. 2C and 3C, heat-killed P. acnes caused a marked increase in the TLR2 expression of cell lines. Bee venom dose-dependently inhibited heat-killed $P$. acnes-induced TLR 2 expression in HaCaT and THP-1 cells. These data suggest that bee venom suppressed the protein levels of TNF- $\alpha$, IL-1 $\beta$ and TLR 2 in heat-killed $P$. acnes-treated HaCaT and THP-1 cells.

Bee venom inhibits the expression of IL-8 and TLR2 in $P$. acnes-treated HaCaT cells. Further investigation using immunofluorescence labeling was performed to assess the effect of bee venom on the expression of IL-8 and TLR 2 in heat-killed P. acnes-treated HaCaT cells (Fig. 4). The cell surface expression of IL- 8 and TLR 2 on HaCaT cells was visualized. Heat-killed $P$. acnes treatment induced the expression of IL-8 and TLR2 in the cytoplasm and plasma membrane of HaCaT cells. However, the concentration of $100 \mathrm{ng} / \mathrm{ml}$ bee venom treatment suppressed the expression of IL- 8 and TLR2 in heat-killed $P$. acnes-treated HaCaT cells. These results showed that bee venom effectively inhibited the secretion of IL-8 and expression of TLR2 in the cytoplasm and plasma membrane of HaCaT cells.

\section{Discussion}

As therapeutic agents for acne, antibiotics have been used to suppress inflammation and action of P. acnes (24). Currently, the available topical therapeutic agents for the treatment of acne contain tetracyclins, clindamycin and erythromycin (25). Several reports suggest that topical therapeutic products have side effects such as occurrence of resistant bacteria, organ damage and skin irritation (26). Therefore, safer and more systematic agents are required.

Bee venom therapy has been used in oriental medicine for the relief of pain and the treatment of inflammatory diseases such as rheumatoid arthritis and multiple sclerosis $(17,27)$. Previous studies have demonstrated the anti-inflammatory effect of bee venom in rheumatoid arthritis, allergic asthma and atherosclerosis $(16,17)$. We have previously reported that bee venom inhibits the development of atherosclerosis in mice induced by injection of lipopolysaccharide (LPS) with the feeding of an atherogenic diet (28). However, a direct role of bee venom in skin inflammation has not been well-established. Therefore, we examined the anti-inflammatory properties of bee venom in skin inflammation induced by heat-killed $P$. acnes using human keratinocytes and monocytes cell lines.

While $P$. acnes induced inflammatory reactions, epidermal and dermal cells contribute to immune and inflammatory reactions by cellular interactions followed by the release of cytokines that constitute the skin immune system (7). Keratinocytes have an important role in the initiation and progression of acne. Keratinocytes are metabolically active cells that can secrete pro-inflammatory cytokines such as IFN- $\gamma$, IL- $1 \beta$ and TNF- $\alpha(2,6)$. Additionally, monocytes activate the induction of pro-inflammatory cytokines by $P$. acnes (5). Several studies demonstrated that keratinocytes and monocytes induce pro-inflammatory cytokines in acne through a TLR2-dependent pathway $(29,30)$.

TLRs play a critical role in the innate immunological response to a variety of microbial pathogens. TLRs may include pattern recognition receptors of the innate immune system (31). TLRs are expressed by various cells of the innate immune system such as monocytes, macrophages and granulocytes (32). Activation of TLRs promotes the production of pro-inflammatory cytokines, prostaglandins, leukotrienes and chemokines (33). Ten human TLRs with different ligand specificities have been identified. TLR4 is associated with CD14 and is mainly involved in mediating LPS-induced cellular signaling of gram-negative bacteria (34). By contrast, TLR2 recognizes lipopeptides from gram-positive bacteria and contributes to the innate immune response of human epidermal keratinocytes (35). In particular, TLR2 is expressed on the cell surface of macrophages surrounding pilosebaceous follicles in acne lesions (30). Several studies have suggested that $P$. acnes may trigger inflammatory cytokine responses in acne via activation of TLR2 (32). During an inflammatory response by $P$. acnes, keratinocytes and monocytes synthesized pro-inflammatory cytokines such as IL-1, IL-8, IFN- $\gamma$ and TNF- $\alpha$ (5). Therefore, we investigated whether bee venom suppresses the expression of TLR 2 and pro-inflammatory cytokines in heat-killed P. acnes-treated HaCaT and THP-1 cell lines. In the present study, heat-killed $P$. acnes increased the secretion of pro-inflammatory cytokines through the active expression of TLR2. By contrast, bee venom treatment suppressed heat-killed $P$. acnes-induced protein levels of TLR2, TNF- $\alpha$ and IL-1 $\beta$, as well as the secretion of IFN- $\gamma$, IL- $1 \beta$, IL- 8 and TNF- $\alpha$.

TNF- $P$. acnes and IL-8 are well-described as pro-inflammatory cytokines induced by $P$. acnes that may play a role in the chemoattraction and maturation of inflammatory cells (36). TNF- $P$. acnes is a multifunctional cytokine that can induce a broad range of secondary pro-inflammatory effects in response to microbial infections. It also promotes keratinocyte proliferation and stimulates angiogenesis (37). In addition, IL-8 is one of the CXC chemokine with mitogenic activity on keratinocytes 
and may play an important role in attracting neutrophils to the pilosebaceous unit (38). Furthermore, it is well-known that $P$. acnes induces keratinocyte IL-8 production through a TLR2-dependent pathway (39). A previous study demonstrated that the receptor blockage with TLR2 reduced the secretion of IL-8. It is, thus, suggested that inhibition of TLR2 activation may be a novel and effective therapeutic strategy for acne (30). The present results showed that $P$. acnes induce the expression of IL- 8 and TLR2 in the cytoplasm and plasma membrane of HaCaT cells. However, bee venom treatment effectively suppressed the expression of IL-8 and TLR2. From these results, it can therefore be assumed that bee venom is able to inhibit TLR2 expression, thereby it perhaps decreases inflammation.

In conclusion, the present results demonstrate that bee venom has effects on anti-inflammatory activity against $P$. acnes in HaCaT and THP-1 cells. Bee venom blocked TLR2 expression and suppressed the production of IFN- $\gamma$, IL-1 $\beta$, IL- 8 and TNF- $\alpha$ induced by $P$. acnes in HaCaT and THP-1 cells. Therefore, we suggest that bee venom is an alternative treatment for antibiotic therapy of acne. However, the anti-inflammatory properties of the bee venom components were not determined. The precise anti-inflammatory mechanism of the bee venom components requires further investigation.

\section{Acknowledgements}

This study was carried out with the support of 'Cooperative Research Program for Agriculture Science and Technology Development (Project No. PJ01132501)' Rural Development Administration, Republic of Korea.

\section{References}

1. Leyden JJ: The evolving role of Propionibacterium acnes in acne. Semin Cutan Med Surg 20: 139-143, 2001.

2. Jappe U: Pathological mechanisms of acne with special emphasis on Propionibacterium acnes and related therapy. Acta Derm Venereol 83: 241-248, 2003.

3. Toyoda M and Morohashi M: Pathogenesis of acne. Med Electron Microsc 34: 29-40, 2001.

4. Leyden JJ, McGinley KJ, Mills OH and Kligman AM: Propionibacterium levels in patients with and without acne vulgaris. J Invest Dermatol 65: 382-384, 1975.

5. Vowels BR, Yang S and Leyden JJ: Induction of proinflammatory cytokines by a soluble factor of Propionibacterium acnes: implications for chronic inflammatory acne. Infect Immun 63 3158-3165, 1995.

6. Raingeaud $\mathrm{J}$ and Pierre J: Interleukin-4 downregulates TNFalpha-induced IL-8 production in keratinocytes. FEBS Lett 579: 3953-3959, 2005.

7. Feliciani C, Gupta AK and Sauder DN: Keratinocytes and cytokine/growth factors. Crit Rev Oral Biol Med 7: 300-318, 1996.

8. Baggiolini M: Chemokines and leukocyte traffic. Nature 392: 565-568, 1998.

9. Ochsendorf F: Systemic antibiotic therapy of acne vulgaris. J Dtsch Dermatol Ges 4: 828-841, 2006 (In German).

10. Eady EA: Bacterial resistance in acne. Dermatology 196: 59-66, 1998.

11. Eady EA, Cove JH, Holland KT and Cunliffe WJ: Erythromycin resistant propionibacteria in antibiotic treated acne patients: Association with therapeutic failure. Br J Dermatol 121: 51-57, 1989.

12. Nam C, Kim S, Sim Y and Chang I: Anti-acne effects of Oriental herb extracts: A novel screening method to select anti-acne agents. Skin Pharmacol Appl Skin Physiol 16: 84-90, 2003.

13. Tan HH: Antibacterial therapy for acne: A guide to selection and use of systemic agents. Am J Clin Dermatol 4: 307-314, 2003.
14. Hider RC: Honeybee venom: A rich source of pharmacologically active peptides. Endeavour 12: 60-65, 1988.

15. Habermann E: Bee and wasp venoms. Science 177: 314-322, 1972.

16. Kwon YB, Lee HJ, Han HJ, et al: The water-soluble fraction of bee venom produces antinociceptive and anti-inflammatory effects on rheumatoid arthritis in rats. Life Sci 71: 191-204, 2002.

17. Kwon YB, Lee JD, Lee HJ, et al: Bee venom injection into an acupuncture point reduces arthritis associated edema and nociceptive responses. Pain 90: 271-280, 2001.

18. Stieger M, Wuthrich B, Wyss S and Kopper E: Clinical picture and diagnosis of bee-venom allergy. A comparison between skin tests and RAST determinations. Hautarzt 29: 632-637, 1978 (In German).

19. Ip SW, Liao SS, Lin SY, et al: The role of mitochondria in bee venom-induced apoptosis in human breast cancer MCF7 cells. In Vivo 22: 237-245, 2008.

20. Orsolic N: Bee venom in cancer therapy. Cancer Metastasis Rev 31: 173-194, 2012

21. Park MH, Choi MS, Kwak DH, et al: Anti-cancer effect of bee venom in prostate cancer cells through activation of caspase pathway via inactivation of NF-kappaB. Prostate 71: 801-812, 2011.

22. Dombrowski Y, Peric M, Koglin S, et al: Honey bee (Apis mellifera) venom induces AIM2 inflammasome activation in human keratinocytes. Allergy 67: 1400-1407, 2012.

23. Han SM, Lee GG and Park KK: Acute dermal toxicity study of bee venom (Apis mellifera L.) in rats. Toxicol Res 28: 99-102, 2012.

24. Guin JD, Huber DS and Gielerak PL: Antibiotic sensitivity of comedonal Propionibacterium acnes. Acta Derm Venereol 59: 552-554, 1979.

25. Webster GF and Graber EM: Antibiotic treatment for acne vulgaris. Semin Cutan Med Surg 27: 183-187, 2008.

26. Humphrey S: Antibiotic resistance in acne treatment. Skin Therapy Lett 17: 1-3, 2012.

27. Park HJ, Lee SH, Son DJ, et al: Antiarthritic effect of bee venom: Inhibition of inflammation mediator generation by suppression of NF-kappaB through interaction with the p50 subunit. Arthritis Rheum 50: 3504-3515, 2004.

28. Lee WR, Kim SJ, Park JH, et al: Bee venom reduces atherosclerotic lesion formation via anti-inflammatory mechanism. Am J Chin Med 38: 1077-1092, 2010.

29. Jugeau S, Tenaud I, Knol AC, et al: Induction of toll-like receptors by Propionibacterium acnes. Br J Dermatol 153: 1105-1113, 2005.

30. Kim J, Ochoa MT, Krutzik SR, et al: Activation of toll-like receptor 2 in acne triggers inflammatory cytokine responses. J Immunol 169: 1535-1541, 2002.

31. Koreck A, Pivarcsi A, Dobozy A and Kemeny L: The role of innate immunity in the pathogenesis of acne. Dermatology 206: 96-105, 2003.

32. Kim J: Review of the innate immune response in acne vulgaris: Activation of Toll-like receptor 2 in acne triggers inflammatory cytokine responses. Dermatology 211: 193-198, 2005.

33. Hari A, Flach TL, Shi Y and Mydlarski PR: Toll-like receptors: Role in dermatological disease. Mediators Inflamm 2010: 437246, 2010.

34. Pivarcsi A, Bodai L, Rethi B, et al: Expression and function of Toll-like receptors 2 and 4 in human keratinocytes. Int Immunol 15: 721-730, 2003.

35. Kollisch G, Kalali BN, Voelcker V, et al: Various members of the Toll-like receptor family contribute to the innate immune response of human epidermal keratinocytes. Immunology 114: 531-541, 2005.

36. Schmidt $\mathrm{N}$ and Gans EH: Tretinoin: A review of its anti-inflammatory properties in the treatment of acne. J Clin Aesthet Dermatol 4: 22-29, 2011.

37. Kock A, Schwarz T, Kirnbauer R, et al: Human keratinocytes are a source for tumor necrosis factor alpha: Evidence for synthesis and release upon stimulation with endotoxin or ultraviolet light. J Exp Med 172: 1609-1614, 1990.

38. Beljaards RC, Van Beek P, Nieboer C, Stoof TJ and Boorsma DM: The expression of interleukin-8 receptor in untreated and treated psoriasis. Arch Dermatol Res 289: 440-443, 1997.

39. Nagy I, Pivarcsi A, Koreck A, Szell M, Urban E and Kemeny L: Distinct strains of Propionibacterium acnes induce selective human beta-defensin-2 and interleukin- 8 expression in human keratinocytes through toll-like receptors. J Invest Dermatol 124: 931-938, 2005. 